\title{
RELATIONSHIP BETWEEN BODY DISSATISFACTION AND EATING DISORDER OF UNIVERSITY STUDENTS
}

\author{
TUAN NOR ATIQAH SYAFIQAH TUAN ABD AZIZ* AND MADIHAH SHUKRI
}

\author{
Department of Psychology and Counselling, School of Social and Economic Development, Universiti Malaysia \\ Terengganu, 21030 Kuala Nerus, Terengganu
}

\section{*Corresponding author: atiqahsyafiqah94@gmail.com}

\begin{abstract}
This study examined the relationship between body dissatisfaction and eating disorder of undergraduate students in University Malaysia Terengganu (UMT). Using stratified random sampling technique, data from 299 respondents was gathered. Body dissatisfaction was measured using Body Shape Questionnaire while eating disorders were assessed using Eating Attitudes Test. Descriptive statistics showed that the majority of the respondents reported no symptom of body dissatisfaction. With regard to eating disorders, respondents reported low levels of dieting, bulimia and oral control, indicating that an eating disorder in this sample was somewhat low. T-test analyses showed that there were no significant gender differences in body dissatisfaction as well as in eating disorders. However, there was evidence to suggest that female respondents had slightly higher level of eating disorder than males. Results of Pearson correlations showed there was significant relationship between body dissatisfaction and total score of eating disorders, dieting, bulimia and oral control subtypes $(\mathrm{r}=.58, \mathrm{p}<.001 ; \mathrm{r}=.64, \mathrm{p}<.001 ; \mathrm{r}=.39, \mathrm{p}<.001 ; \mathrm{r}=.18, \mathrm{p}<.001$; respectively) in that, higher level of body dissatisfaction was significantly related to increased risk of eating disorders.
\end{abstract}

Keywords: body dissatisfaction, eating disorders, gender differences, university students

\section{Introduction}

On a global level, at least 10 million women and one million men are struggling with eating disorders and a million more fighting with binge eating problems (National Association of Eating Disorders, 2011). These psychological illnesses are characterized by "abnormal eating patterns and cognitive distortions related to food and body weight, which adversely affect nutritional status and lead to medical complications and impaired health status and function" (Spear, 2006; pp, 541). The most common types of eating disorders are Anorexia Nervosa, Bulimia Nervosa, Binge Eating Disorder, and Rumination Disorder (American Psychiatric Association, 2013).

While eating disorders usually occur in adolescents or early adults, there are a few individuals who have suffered from this psychological problem since childhood or adulthood (Spearing, 2001). Causes of eating disorders are incompletely understood (van Furth, van der Meer, \& Cowan, 2016). However, Striegel and Bulik (2007) found that socio-cultural factors plus biological factors are among the biggest contributors to the disruption of individual's eating patterns. In terms of socio-cultural factor, societies that equate beauty with thin body will increase individuals' tendency to control body weight (Polivy \& Herman, 2002), and thus contribute to disordered eating. In an attempt to understand eating disorder within cultural context, the Cognitive Behavioural Theory (Fairburn, 1981) focuses on the understanding of thoughts, feelings, and behaviors that contribute to disorders in terms of body image, fear of obesity, and failure to control nutrition (Ann et al.,
2013). It has been proposed that individuals who are suffering from eating disorders might have disorders in terms of thoughts and images related to weight, body shape such as body dissatisfaction, and food (Ann et al., 2013). When body dissatisfaction comes from the social pressure to achieve the target weight and shape combined with low levels of self-confidence and the importance of perfection, it will affect the development of eating disorders (Fairburn, et al., 2008; Vohs et al., 2001).

Despite the fact that eating disorders are widely recognized as serious health threats that affect global population, surprisingly, there is no complete data on eating disorders in Malaysia (Ramli et al., 2008). It has been suggested that increasing globalization and exposure to western media have contributed to the increase rate of eating disorders in non-Western countries (Makino et al., 2004). Western studies in particular have shown that body dissatisfaction is often recognized as the single strongest predictor of eating disorder symptomatology. For instance, meta-analytic review (Grabe et al., 2008) has identified body dissatisfaction as one of the most consistent and robust risk factors for eating disorders such as bulimia based on prospective and longitudinal designs. However, empirical research (Ramli et al., 2008, Tan \& Yew, 2012) to address this issue in Malaysia is scarce. Hence, this study examined the relationship between body dissatisfaction and eating disorder of university students. 


\section{Materials and Methods Sample}

The population of this study was undergraduate students in the School of Social and Economic Development, Universiti Malaysia Terengganu, for the 2016/17 session totaling 1343. Data was collected from 299 students ( 81 males, $27.1 \%$; 218 females, $72.9 \%$ ), using stratified random sampling technique. Their ages were between 19 and 25. Their BMI status showed that $47(15.7 \%)$ of the respondents were underweight, $178(59.5 \%)$ were at normal weight, $59(19.7 \%)$ were overweight, and 15 $(5.0 \%)$ were obese.

\section{Research Instruments Demographic Data}

Respondents completed standard demographic measures (gender, age, ethnicity, year of study). Body mass index (weight (kg)/(height (m)2)) was calculated based on selfreported height and weight.

\section{Body Dissatisfaction}

The Body Shape Questionnaire (BSQ; Cooper et al., 1987) was used to asses the level of body dissatisfaction of respondents. This measure contains 34 items related to people's perceptions of their body weight and shape. Items were scored as (1) never to (6) always. An example of an item was "Have you been so worried about your shape that you have been feeling you ought to diet?'. The total score was calculated by adding up the score for each item. The total score was used to quantify respondents' concerns with their body image, namely no concern (less than 110$)$, mild (111 to 138$)$, moderate (139 to 167 ) and severe (more than 167), according to standards of the original measure (Cooper et al., 1987). The BSQ measure was realiable $(\alpha=.968)$

\section{Eating Disorders}

Eating disorders were assessed using Eating Attitudes Test (EAT-26) developed by Garner et al. (1982). The scale has 26 items. There are subscales of dieting (e.g., I am terrified about being overweight), bulimic behaviors (e.g., I feel extremely guilty after eating), and selfcontrol of eating behavior (e.g., I avoid eating when I am hungry). Items were scored (1) Always to (6) Never. The total score was classified into 3 categories: low (less than 53), moderate (53 to 104) and high (more than 104). This measure was reliable $(\alpha=.825)$.

\section{Data Analysis}

All statistical analyses were completed using Statistical Package for the Social Sciences (SPSS). Descriptive statitistics including means and standard deviation, and inferential statistics such as independent t-test and Pearson correlation, were computed.

\section{Results and Discussion \\ Prevalence of Body Dissatisfaction}

The prevalence of body dissatisfaction is shown in Table 1. Majority $(70.6 \%)$ of the respondents reported no symptom of body dissatisfaction, $45(15.1 \%)$ mild, 36 (12\%) moderate and $7(2.3 \%)$ severe. The prevalence of body dissatisfaction found in this study was clearly lower than in the previous Western study (Bearman et al., 2006) which found that approximately $50 \%$ of girls and undergraduate women were dissatisfied with their bodies.

Table 1: Prevalence of body dissatisfaction symptoms

\begin{tabular}{ll}
\hline Body Dissatisfaction & N $(\%)$ \\
\hline No concern & $211(70.6 \%)$ \\
Mild & $45(15.1 \%)$ \\
Moderate & $36(12.0 \%$ \\
Severe & $7(2.3 \%)$ \\
\hline
\end{tabular}

\section{Prevalence of Eating Disorders by Subtype}

As can be seen in Table 2, the results showed relatively low prevalence of dieting, bulimia and self- control, ranging from $74(24.7 \%)$ to $85(28.4 \%)$ for moderate symptoms, to $21(7 \%)$ to $36(12 \%)$ for high symptoms of each subscale. For overall eating disorders, $73(24.4 \%)$ of them had moderate symptoms, while $15(5.0 \%)$ had severe symptoms. 
Table 2: Prevalence of eating disorders by subtype

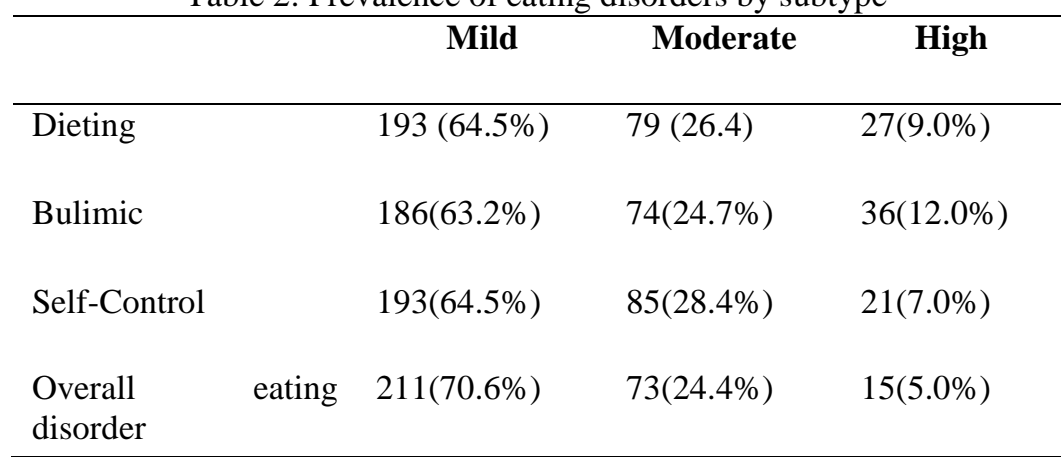

\section{Body Dissatisfaction and Eating Disorders by Gender}

Differences in body dissatisfaction by gender are presented in Table 3. In the current study, it was found that body dissatisfaction did not differ significantly across gender $\mathrm{t}(297)=1.63, \mathrm{p}>.01$, though men $(\mathrm{M}=$ 4.63) reported higher dissatisfaction than female $(\mathrm{M}=$ 4.40). Previous Western studies (e.g. Neighbors, \& Sobal, 2007, Santana, 2013), however, found that females expressed greater body dissatisfaction than males. For instance, Santana (2013) found gender differences in body dissatisfaction, with the prevalence of $26.6 \%$ among females and $10 \%$ among males. The results of the current study coincide with those of Tan and Yew (2012), which found that both genders had the risk of experiencing eating disorders due to dissatisfaction with their body shape. Gender differences in body disssatisfaction may be explained by the fact that men are more keen to have masculine body while women want to be thinner (Hatoum \& Belle, 2004). Mansfield (2012) stated that both men and women with low self-esteem reported dissatisfaction with the shape of their body.

Table 3: Differences in body dissatisfaction by gender

\begin{tabular}{lllll}
\hline & Gender & Mean & SD & t \\
\hline Body dissatisfaction & Males & 4.63 & .95 & 1.63 \\
& Females & 4.40 & 1.13 & \\
\hline
\end{tabular}

Differences in eating disorders by gender are presented in Table 4. It was found that females reported higher scores in subtype and overall eating disorders. Nonetheless, there were no significant gender differences in the prevalence of any of the eating disorders. The results confirmed the study conducted by Massaldjieva et al. (2017) involving early adult samples. Our findings therefore provide important insight on the rising prevalence of eating problem among males amidst growing literature reporting gender disparity in the prevalence of eating disorder, where previous research consistently reported significantly higher rates of eating disorders among females (Strother et al., 2012). Other study suggested that the extent to which gender differences exist depended on the particular eating disorder symptoms under investigation (Striegel-Moore et al., 2009).

Table 4: Differences in eating disorders by gender

\begin{tabular}{lllll}
\hline & Gender & Mean & SD & t \\
\hline Dieting & Males & 4.19 & .93 & -1.19 \\
& Females & 4.33 & .87 & \\
Bulimic & Males & 4.39 & 1.04 & .45 \\
\multirow{5}{*}{ Self-Control } & Females & 4.33 & .98 & \\
& Males & 4.24 & .90 & -1.08 \\
Eating disorders & Females & 4.35 & .78 & \\
& Males & 4.25 & .81 & -.92 \\
& Females & 4.34 & .68 & \\
\hline
\end{tabular}

\section{Relationships between Body Dissatisfaction and Eating Disorders by Subtype}

Table 5 shows the correlations between body dissatisfaction and eating disorders (dieting, bulimic, and self-control). Analysis based on the subscales showed significant positive correlation between the body dissatisfaction and dieting subscale $(r=.649, \mathrm{p}<.001)$, bulimic subscale $(\mathrm{r}=.390, \mathrm{p}<.001)$, and self-control subscale $(\mathrm{r}=.186, \mathrm{p}<.001)$. Correlation between overall body dissatisfaction and eating disorder was high and significant $(r=.581, p<.001)$. Thus, higher level of body dissatisfaction is related to increased symptoms of overall eating disorder and each subtype. 
Table 5: Correlations Between Body Dissatisfaction and Eating Disorders

$\begin{array}{llllll}\text { Variables } & 1 & 2 & 3 & 4 & 5\end{array}$

\begin{tabular}{llllll}
\hline (1) Body Dissatisfaction & - & & & \\
(2) Dieting & $.64^{* *}$ & - & & \\
(3) Bulimic & $.39^{* *}$ & $.41^{* *}$ & - & & \\
(4) Self-Control & $.18^{* *}$ & $.40^{* *}$ & $.56^{* *}$ & - & \\
(5) Eating disorder & $.58^{* *}$ & $.87^{* *}$ & $.75^{* *}$ & $.73^{* *}$ & - \\
\hline
\end{tabular}

$* \mathrm{p}<.05 ; * * \mathrm{p}<.001$

Our findings are supported by a few studies (Grabe et al., 2008; Tan \& Yew, 2012) which found a positive relationship between body disorder and eating disorders. In addition, a recent study (Munkholm et al., 2016) also indicated that problematic eating behaviours were associated with excess weight, body discomfort, and mental disorders among early adolescents. It has been proposed that the key factor in the development and maintenance of eating disorder is the dysfunction in evaluating self-worth (American Psychiatric Association, 2000). Based on Cognitive Behaviour Theory (Fairburn, 1981), individuals with eating disorders judge themselves largely based on their eating habits, shape or weight and their ability to control them (Fairburn et al., 2008). In particular, in the development of excessive weight and body shape concerns, one of the principal factors behind body dissatisfaction may originate from the pressure to emulate the Western body ideal, ultra thin for women and muscular for men (Hogan, $\&$ Strasburger, 2008). There is evidence to suggest that such pressures may come from various sociocultural

\section{References}

American Psychiatric Association (2000). Diagnostic and statistical manual of mental disorders (4th ed.). Washington, DC: American Psychiatric Association Text revision.

American Psychiatric Association. (2013). Diagnostic and statistical manual of mental disorders (5th ed). Arlington, VA: American Psychiatric Publishing.

Ann, M. K., Sherl, L. J., Gerald, D., \& John, N. (2013). Abnormal Psychology: Twelfth Edition - DSM5 Update. Wiley, 334-346.

Bearman, S. K., Presnell, K., Martinez, E., \& Stice, E. (2006). The skinny on body dissatisfaction: A longitudinal study of adolescent girls and boys. Journal of Youth and Adolescence, 35(2), 217229.

Calado, M., Lameiras, M., Sepulveda, A. R., Rodriguez, Y., \& Carrera, M. V. (2011). The association between exposure to mass media and body factors including parents, friends, and the media (Calado et al., 2011). Hence, efforts to promote positive body image and healthy lifestyle need to be integrated into health intervention programmes as a general practice as well as in school and university settings with the goal of helping to prevent eating disorders (Calado et al., 2011; National Eating Disorder Collaboration, 2016).

\section{Conclusion}

Overall, the results of this study confirmed the Western study finding on the relationship between body dissatisfaction and eating disorders of young adults. Further studies are needed to document the important determinants of body dissatisfaction to aid the prevention and intervention of disordered eating.

\section{Acknowledgements}

The authors would like thank the participants of this study for their contribution in terms of time and effort.

dissatisfaction among Spanish adolescents. Women's Health Issues, 21(5), 390-399.

Cooper, P. J., Taylor, M. J., Cooper, Z., \& Fairbum, C. G. (1987). The development and validation of the Body Shape Questionnaire. International Journal of Eating Disorders, 6(4), 485-494.

Fairburn, C. G. (1981). A cognitive behavioural approach to the management of bulimia. Psychological Medicine, 11, 707-711.

Fairburn, C. G., Cooper, Z., Shafra, R., Bohn, K., \& Hawker, D. M. (2008). Clinical perfectionism, core low self-esteem and interpersonal problems. In C. G. Fairburn (Ed.), Cognitive behaviour theraphy and eating disorders (pp. 197-220). New York: Guilford Press.

Garner, D. M., Olmsted, M. P., Bohr, Y., \& Garfinkel, P. E. (1982). The eating attitudes test: psychometric features and clinical correlates. Psychological Medicine, 12(4), 871-878.

Grabe, S., Ward, L. M., \& Hyde, J. S. (2008). The role of the media in body image concerns among women: a 
meta-analysis of experimental and correlational studies. Psychological Bulletin, 134(3), 460-476.

Hatoum, I. J., \& Belle, D. (2004). Mags and abs: Media consumptionand bodily concerns in men. Sex Roles, 51, 397-407.

Hogan, M. J., \& Strasburger, V. C. (2008). Body image, eating disorders, and the media. Adolescent Medicine, 19, 521-546.

Makino, M., Tsuboi, K., \& Dennerstein, L. (2004). Prevalence of eating disorders: a comparison of Western and non-Western countries. Medscape General Medicine, 6(3).

Massaldjieva, R. I., Bakova, D., Semerdjieva, M., Torniova, B., \& Tilov, B. (2017). Disordered Eating Attitudes and Behaviors: Gender Differences in Adolescence and Young Adulthood. Journal of Women's Health Care, 6(368), 21670420 .

Mansfield, T. (2012). Gender Differences in BodyEsteem, Body Dissatisfaction and the Effects of the Medias 'Thin Ideal'. Department of Psychology, DBS School of Arts.

Munkholm, A., Olsen, E. M., Rask, C. U., Clemmensen, L., Rimvall, M. K., Jeppesen, P., ... \& Skovgaard, A. M. (2016). Eating behaviours in preadolescence are associated with body dissatisfaction and mental disorders-Results of the CCC2000 study. Appetite, 101, 46-54.

National Association of Eating Disorders (2011). Retrieved July 18, 2011, from www.nationaleatingdisorders.org/index.ph p.

National Eating Disorder Collaboration (2016). Eating Disorders in Schools: Prevention Early Identification and Response. Second Edition. Retrieved from http://www.nedc.com.au/files/Resources/Teachers \%20Resource.pdf.

Neighbors, L. A., \& Sobal, J. (2007). Prevalence and magnitude of body weight and shape dissatisfaction among university students. Eating behaviors, 8(4), 429-439
Polivy, J., \& Herman, C. P. (2012). Causes of eating disorders. Annual Review of Psychology, 53, 187-213.

Ramli, M., Jamaiyah, H., Azimah, N., Khairani, O., \& Adam, B. (2008). Cross-Cultural Adaptation and Validation of the Bahasa Malaysia Version of the Eating Disorder Examination Questionnaire (EdeQ). Malaysian Journal of Psychiatry, 17(2).

Santana, M. L. P. D., Silva, R. D. C. R., Assis, A. M. D. O., Raich, R. M., Machado, M. E. P. D. C., Pinto, E. D. J., ... \& Ribeiro Júnior, H. D. C. (2013). Factors associated with body image dissatisfaction among adolescents in public schools students in Salvador, Brazil. Nutricion Hospitalaria. 28 (3): 747-755.

Spear, B.A. (2006) in Handbook of Clinical Nutrition (Fourth Edition), Eating Disorders, pp 541-553.

Spearing, M. (2001). Eating Disorders: Facts about Eating Disorders and the Search for Solutions. Retrieved February 23, 2017, from http://www.nimh.nih.gov/publicat/ eatingdisorders.cfm

Striegel-Moore, R. H., \& Bulik, C. M. (2007). Risk factors for eating disorders. American Psychologist, 62(3), 181.

Strother, E., Lemberg, R., Stanford, S. C., \& Turberville, D. (2012). Eating disorders in men: underdiagnosed, undertreated, and misunderstood. Eating disorders, 20(5), 346-355.

Tan, S. Y., \& Yew, W. P. (2012). The relationship between body dissatisfaction and eating disorder among exercisers. SEGi Review, 5, 132-56.

Van Furth, E. F., van der Meer, A., \& Cowan, K. (2016). Top 10 research priorities for eating disorders. The Lancet Psychiatry, 3(8), 706-707.

Vohs, K. D., Voelz, Z. R., Pettit, J. W., Bardone, A. M., Katz, J., Abramson, L. Y., Heatherton, T. F., \& Joiner, T. E. (2001). Perfectionism, body dissatisfaction, and self-esteem: An interactive model of bulimic symptom development. Journal of Social \& Clinical Psychology, 20, 476-497. 